\title{
Size of RJVs and Degree of Cooperation in Product Development
}

\section{Citation}

Bourreau, Marc, Pinar Dogan, and Matthieu Manant. 2010. Size of RJVs and Degree of Cooperation in Product Development. HKS Faculty Research Working Paper Series RWP10-047, John F. Kennedy School of Government, Harvard University

\section{Published Version}

http://web.hks.harvard.edu/publications/workingpapers/citation.aspx?Publd=7503

\section{Permanent link}

http://nrs.harvard.edu/urn-3:HUL.InstRepos:4621101

\section{Terms of Use}

This article was downloaded from Harvard University's DASH repository, and is made available under the terms and conditions applicable to Other Posted Material, as set forth at http:// nrs.harvard.edu/urn-3:HUL.InstRepos:dash.current.terms-of-use\#LAA

\section{Share Your Story}

The Harvard community has made this article openly available.

Please share how this access benefits you. Submit a story.

Accessibility 


\title{
Size of RJ Vs and Degree of Cooperation in Product Development Faculty Research Working Paper Series
}

\author{
Marc Bourreau
}

Telecom ParisTech and CREST-LEI

\section{PInar Dogan}

Harvard Kennedy School

\section{Matthieu Manant}

Université Paris Sud XI

\section{December 2010 RWP10-047}

The views expressed in the HKS Faculty Research Working Paper Series are those of the author(s) and do not necessarily reflect those of the John F. Kennedy School of Government or of Harvard University. Faculty Research Working Papers have not undergone formal review and approval. Such papers are included in this series to elicit feedback and to encourage debate on important public policy challenges. Copyright belongs to the author(s). Papers may be downloaded for personal use only. 


\title{
Size of RJVs and Degree of Cooperation in Product Development*
}

\author{
Marc Bourreau ${ }^{\dagger}$ Pınar Doğan
}

December 1, 2010

\begin{abstract}
In this paper we provide a model of Research Joint Venture (RJV), and study the incentives of competing firms to cooperate in product development. Firms that participate in the RJV decide on the product components for joint development, i.e., they decide on how much to cooperate. We consider three cases: (i) an RJV with an exogenous size and an endogenous scope, (ii) an RJV with an endogenous size and an exogenous scope, and (iii) an RJV with an endogenous size and scope. Using numerical simulations we show that, on average, there is a negative relationship between the size and the scope of the RJV in both cases (i) and (ii). In case (iii), we find a positive relationship between the equilibrium size and the equilibrium scope of the RJV. Furthermore, both the equilibrium size and scope of the RJV are increasing with the industry size.
\end{abstract}

Keywords: R\&D Cooperation, RJV, Product Development.

JEL Codes: L1, O3.

\footnotetext{
${ }^{*}$ We would like to thank Paul Belleflamme, Nisvan Erkal, Nicolas Houy and Patrick Waelbroeck for valuable comments and suggestions. We also thank the audiences at the 2008 EARIE Conference (Toulouse, France) and at the 2009 International Industrial Organization Conference (Boston, USA), and the seminar participants at Mines ParisTech (Paris, France) and CORE (Louvain-la-Neuve, Belgium). We also thank Katie Naeve for her editorial assistance.

${ }^{\dagger}$ Telecom ParisTech, Department of Economics and Social Sciences, and CREST-LEI, Paris. Email: marc.bourreau@telecom-paristech.fr.

${ }^{\ddagger}$ Harvard Kennedy School of Government, Harvard University. E-mail: pinar_dogan@hks.harvard.edu.

${ }^{\S}$ Université Paris Sud XI. Email: matthieu.manant@u-psud.fr.
} 


\section{Introduction}

In many industries, especially in the automobile sector, rival firms team up to develop product components which are then used to manufacture competing final-products. Cooperation among these firms is not "full" in the sense that firms do not develop an entire product jointly, but only some components of it. ${ }^{1}$ For example, it is common for automakers to team up to develop product components such as hybrid systems, fuel-cell systems, transmissions systems, or break systems. $^{2}$ While firms cooperate in developing particular product components, each firm pursues its independent R\&D for other product components that are necessary to develop the end-product. In such cases-unlike the standard treatment of the theoretical literature-firms do not make zero-one decisions on cooperation in product development. Instead, firms decide on the product components that they wish to develop jointly, that is, on the degree of cooperation in product development. ${ }^{3}$

In this paper, we consider an oligopolistic market and study the degree of cooperation in product development that might emerge among competing firms. ${ }^{4}$ Firms that participate in the Research Joint Venture $^{5}$ (RJV) decide on product components for joint development. We assume that a higher degree of cooperation (i.e., a larger number of product components developed jointly) leads to a lower degree of product differentiation, as it will imply a larger number of common product components in participant firms' end-products. Therefore, we consider intensified competition in the product market as a major cost of forming cooperative alliances in product development. ${ }^{6}$ Such a cost may be significant, particularly in markets where product differentiation matters for end consumers, and might partly explain why cooperation among rivals does not always emerge. ${ }^{7}$

We consider three cases: (i) an RJV with an exogenous size and an endogenous scope; (ii) an RJV with an endogenous size and an exogenous scope; and (iii) an RJV with an endogenous size and scope. Using numerical simulations we show that, on average, there is a negative relationship

\footnotetext{
${ }^{1}$ One exception is production of "twin automobiles." See Lado et al. (2004) for examples of identical cars that are sold under different brand names.

${ }^{2}$ For example, Suzuki and GM have teamed up for the development of a hybrid system as well as fuel-cell systems. The collaboration will end by February 2010. See Wall Street Journal, "Suzuki to End Hybrid Work With GM," January 15, 2010.

${ }^{3}$ We also refer the degree of cooperations as the "scope" of the cooperative agreement.

${ }^{4}$ See Bourreau and Doğan (2010), who study "partial" cooperation, along with full cooperation, between two competing firms.

${ }^{5}$ In this paper we use RJV as a broader term that includes any type of cooperative alliances aimed at joint product development. We do not consider RJVs that aim at cost reduction.

${ }^{6}$ The way we model cost of cooperation is similar to Lambertini et al. (2002), but our setting differs in that the cost of cooperation varies with the degree of cooperation.

${ }^{7}$ See also Röller et al. (2007), who show that "asymmetries" among the firms (in marginal cost) may lead to a disincentive to form an RJV.
} 
between the size and the scope of the RJV in both cases (i) and (ii). In case (iii), we find a positive relationship between the equilibrium size and the equilibrium scope of the RJV. Furthermore, both the equilibrium size and scope of the RJV are increasing with the industry size.

These results hinge on four different effects. First, there is a development cost effect, which introduces a complementarity between the size and the scope of the RJV. A higher number of member firms implies larger savings from development costs, which gives member firms incentives to set a larger scope for the RJV. Similarly, an RJV with a larger scope gives incentives to involve a larger number of firms. Second, a larger number of participants in the RJV has a negative direct effect on the profit of member firms, as it shifts their demand inwards due to a lower degree of differentiation. Third, a larger number of member firms has also a positive indirect effect on the profit of member firms; this is because, as the demand for RJV members shifts inward, each member firm reduces its output, which impacts positively the other firms' profits. The magnitude of the direct and indirect effects, hence, the total effect of increasing the size of the RJV, depends on the scope of the RJV (i.e., on the degree of cooperation). Fourth, there is a sensitivity-of-profits effect; as the size of the RJV increases, member firms' profits become less sensitive to differentiation for low degrees of differentiation and more sensitive for high degrees of differentiation. Therefore, when the degree of differentiation is low (resp., high) and the size of the RJV increases, member firms have an incentive to choose a larger (resp., smaller) scope for the RJV.

Our paper is related to the theoretical literature on cooperative R\&D and formation of RJVs. The existing literature addresses a large set of interesting questions, ranging from how private and social incentives for cooperation compare in different settings (e.g., in the presence of uncertainty, synergies, endogenous as well as exogenous spillovers, and with and without an innovation race) $)^{8}$ to how cooperation may affect incentives to maintain post-innovation collusion. ${ }^{9}$ The main features that differentiate our model from those studied in the existing literature are as follows:

1. an RJV is formed for cooperation in product development;

2. an RJV can be formed by a subset of firms that compete in the oligopolistic industry;

3. participating firms decide on the degree of cooperation (i.e., on the scope of RJV); and

4. a high degree of cooperation intensifies post-R\&D competition among RJV members.

\footnotetext{
${ }^{8}$ Among others, see Suzumura (1992), Choi (1993), Kamien et al (1992), and Kamien and Zang (2000).

${ }^{9}$ See Martin (1996), Cabral (2000), and Lambertini et al (2002).
} 
First, with very few exceptions, the literature focuses on process R\&D (i.e., R\&D efforts for cost reduction) rather than product development. Notable exceptions are Motta (1992) and Lin and Saggi (2002) both of which consider a duopoly setting with a binary choice for cooperation.

Second, among those studies that consider an oligopolistic setting with process $R \& D$, the majority consider an industry-wide RJV. ${ }^{10}$ Papers that consider a subset of the firms in the industry are Katz (1986), Poyago-Theotoky (1995), and Falvey et al. (2006). Katz (1986) analyzes cooperation for process innovation with spillovers, where the number of participants of the RJV can range from two to the total number of firms in the industry. Poyago-Theotoky (1995) analyzes the optimal size of a research joint venture, in an oligopolistic setting with homogeneous goods, process R\&D and spillovers. Falvey et al. (2006) adopt a similar setting, and study the impact of coordination costs on the equilibrium size of the RJV.

Third, the majority of papers consider cooperation decisions as binary: firms either cooperate or they don't. Two exceptions are Goyal et al. (2008) and Bourreau and Doğan (2010). Goyal et al. (2005) study the relationship between $R \& D$ investments in joint projects and in-house projects. Bourreau and Doğan (2010) use a setting similar to that in this paper, and study the interaction between cooperation in product and process R\&D in a duopolistic setting.

Finally, with very few exceptions (notably Vilasuso and Frascatore (2000), Lambertini et al. (2002), and Falvey et al. (2006)) the literature does not consider any economic cost of cooperation; ${ }^{11}$ it concludes that cooperation is, at least in a weak sense, desirable for firms since they can always replicate the non-cooperative equilibrium.

The remainder of the paper is organized as follows. In Section 2, we set up our oligopoly model of RJV in product development. We study the three different cases stated above in separate sections: in Section 3 to 5. In Section 6 we discuss social welfare in the three different cases. Finally, we conclude.

\footnotetext{
${ }^{10}$ See, for example, Motta (1992), Suzumura (1992), Yi (1995), and Kamien et al. (1992). Suzumura (1992) extends the model of d'Aspremont and Jacquemin (1988) to oligopolies. Kamien et al. (1992) analyze $n$-firm oligopolies and compare four scenarios of R\&D activity in terms of social welfare.

${ }^{11}$ Vilasuso and Frascatore (2000) consider an exogenous fixed cost of forming an RJV, which can be attributed to its management or auditing. In Lambertini et al. (2002), when firms cooperate in product innovation they develop a single product, whereas they produce differentiated products when they do not cooperate. Therefore, cooperative R\&D comes with a cost; it leads to fierce competition post-innovation unless firms collude at the competition stage. Falvey et al. (2006) introduce coordination costs to run an RJV in an oligopolistic setting. The coordination costs are modeled through the marginal cost of process $R \& D$; the authors assume that the marginal cost of process $R \& D$ increases with the number of participants in the RJV. Coordination costs tend to decrease the R\&D of members of the RJV, as well as reduce the equilibrium size of the RJV.
} 


\section{A model of RJV for product development}

Consider an oligopoly with $n$ ex-ante identical firms, where the final product is composed of a continuum of product components normalized to 1 . We study an RJV formed by $k$ firms, with $2 \leq k \leq n$, for joint development of product components. Without loss of generality, we order the firms so that firms $i=1, \ldots, k$ are the RJV members and firms $j=k+1, \ldots, n$ are the non-member firms.

While $(n-k)$ firms develop their entire final products individually, RJV members cooperatively decide on the product components that they develop jointly (i.e., on the degree of commonality ${ }^{12}$ in their products), $\alpha$, with $\alpha \in[0,1]$. We assume that the set of jointly developed components is $[0, \alpha]$, that is, the firms cooperate to develop the first $\alpha$ components. The degree of commonality, $\alpha$, represents the degree of cooperation in product development; $\alpha=0$ corresponds to the degenerate case in which there is no cooperation within the RJV, whereas $\alpha=1$ corresponds to the case in which the RJV members develop the entire final product jointly.

The degree of cooperation in product development determines both the product development costs and the degree of product differentiation.

Product development costs The firms have the same cost of developing product components. The marginal development cost of the $m^{\text {th }}$ component is denoted by $\eta(m)$, and $\eta(\cdot)$ is continuous. Letting $d(m)$ denote the total cost of developing the first $m$ product components, we have

$$
d(m)=\int_{0}^{m} \eta(x) d x
$$

RJV members share the development cost of common components, $d(\alpha)$, equally. Each firm also carries in-house $\mathrm{R} \& \mathrm{D}$ to develop the remaining product components, for which the firm bares the full cost of development. Let $D_{R}(k, \alpha)$ denote the total development cost for a member of the RJV, for a given degree of cooperation of $\alpha$. We have

$$
D_{R}(k, \alpha)=\frac{d(\alpha)}{k}+(d(1)-d(\alpha))
$$

\footnotetext{
${ }^{12}$ We use the degree of cooperation, the degree of commonality, and scope of the RJV interchangeably throughout the paper.
} 
which can be rewritten as

$$
D_{R}(k, \alpha)=d(1)-\frac{k-1}{k} d(\alpha) .
$$

The first term in (1) represents the cost of developing the entire product alone, and the second term represents the economies from cooperation in product development that is enjoyed by the RJV members. The total development cost decreases with the degree of cooperation, $\alpha$, and with the size of the RJV, $k .^{13}$ The development cost for non-member firms is $D_{-R}=d(1)$.

In this setting, the mere benefit of cooperation in product development is due to cost sharing, and there are no synergies from joint product development. Furthermore, we have $(d(1)-d(\alpha))+$ $d(\alpha)=d(1)$, and hence, there are no economies (or diseconomies) of scope in developing the product components.

Degree of product differentiation We model the degree of product differentiation between the product of firm $i$ and the product of firm $j$, so that it depends on the "distance" between the products of these two firms. Assume that component $m$ of firm $i$ 's product takes value $\alpha_{i}(m)=i$ if it is developed in-house, and value $\alpha_{i}(m)=0$ if it is developed jointly with the other firms. Also, let $\xi$ be the measure of the set of jointly developed components, $\left\{m \in[0,1] \mid \alpha_{i}(m)=0\right\}$. Then, we have $\alpha=\xi$, where $\alpha$ represents the degree of commonality between the firms' products. Finally, let $\Delta=1-\xi$. It can be verified that $\Delta$ represents a distance between the products of firm $i$ and firm $j .{ }^{14}$

The degree of differentiation between the firms' products, $s$, is then determined by the degree of commonality, $\alpha$. We assume that differentiation is at a minimum when the distance between the products is nil, (i.e., $s(1)=s_{\min }$ ) and at a maximum when the distance is equal to 1, (i.e., $\left.s(0)=s_{\max }\right)$. We assume that the degree of differentiation between members of the RJV, denoted by $s$, is decreasing with $\alpha$, that is, $s=s(\alpha)$ and $\partial s(\alpha) / \partial \alpha<0$, with $s \in\left[s_{\min }, s_{\max }\right], s_{\min } \in\left[0, s_{\max }\right)$ and $s_{\max }<1 .{ }^{15}$ Since a non-member firm (i.e., outside the RJV) does not share any common component with the other firms, the distance between its product and any other firm's product is equal to 1, and hence, the degree of differentiation between this firm and any other firm is equal

\footnotetext{
${ }^{13}$ Indeed, we have $D_{R}(l, \alpha) \geq D_{R}(k, \alpha)$ for all $l \leq k$.

${ }^{14}$ This is true as we have (i) $\Delta \geq 0$, (ii) $\Delta=0$ if and only if the products of firms $i$ and $j$ are identical (i.e., $\alpha=1$ ), and (iii) $\Delta(i, j)+\Delta(j, k) \geq \Delta(i, k)$ is always true.

${ }^{15}$ We assume that $s_{\min } \geq 0$, that is, even when all product components are developed jointly by the RJV firms $(\alpha=1)$, their end-products are not necessarily perceived as perfect substitutes by the consumers. See, for example, Sullivan (1998) and Lado et al. (2004) on how brand names affect the demand for "twin automobiles." Twin automobiles are identical products that are sold under different brand names (e.g., Citroen Evasion, Fiat Ulysses, and Peugeot 806), for which the consumers' willingness to pay is not necessarily the same.
} 
to $s_{\max }$.

Demand We generalize the demand system provided by Dixit (1979) and Singh and Vives (1984). The utility of the representative consumer is given by

$$
U(\boldsymbol{q}, m)=a \sum_{i=1}^{n} q_{i}-\frac{1}{2} \sum_{i=1}^{n}\left(q_{i}\right)^{2}-\sum_{i=1}^{n-1} q_{i} \sum_{j=i+1}^{n}\left(1-s_{i j}\right) q_{j}+m
$$

where $s_{i j}$ is the degree of differentiation between the product of firm $i$ and the product of firm $j$, $\boldsymbol{q}=\left(q_{1}, \ldots, q_{n}\right)$ is the vector of quantities, and $m$ is the numeraire good. Then, the inverse demand for an RJV member firm $i=1 \ldots k$ is

$$
p_{i}=a-q_{i}-\sum_{\substack{j=1 \\ j \neq i}}^{k}(1-s) q_{j}-\sum_{j=k+1}^{n}\left(1-s_{\max }\right) q_{j}
$$

where $q_{i}$ and $p_{i}$ denote the quantity and price of firm $i$ and $q_{j}$ the quantity of firm $j$. The inverse demand for a non-member firm $l=k+1 \ldots n$ is

$$
p_{l}=a-q_{l}-\sum_{\substack{j=1 \\ j \neq l}}^{n}\left(1-s_{\max }\right) q_{j}
$$

Finally, once the products are developed, firms produce at a constant marginal cost of $c$ and compete in the product market with quantities. The net (resp., gross) profit of an RJV member firm is denoted by $\Pi_{R}$ (resp., $\pi_{R}$ ), and the net (resp., gross) profit of a non-member firm is denoted by $\Pi_{-R}$ (resp., $\pi_{-R}$ ). The net profits for RJV member firms and non-member firms are

$$
\Pi_{R}(k, \alpha)=\pi_{R}(k, s(\alpha))-D_{R}(k, \alpha),
$$

and

$$
\Pi_{-R}(k, \alpha)=\pi_{-R}(k, s(\alpha))-d(1),
$$

respectively. We assume that the market is viable; in equilibrium $\Pi_{R}(k, \alpha), \Pi_{-R}(k, \alpha) \geq 0$ for any $k$ and $\alpha$.

We consider three cases: (i) an RJV with an exogenous size and an endogenous degree of cooperation (scope); (ii) an RJV with an endogenous size and an exogenous degree of cooperation (scope); and (iii) an RJV with an endogenous size and an endogenous degree of cooperation (scope). 


\section{An RJV with an exogenous size and an endogenous scope}

In this subsection we consider an RJV with an exogenous size, $\bar{k}$, and study the equilibrium degree of cooperation. The equilibrium gross profits of both member and non-member firms, $\pi_{R}^{*}(\bar{k}, s)$ and $\pi_{-R}^{*}(\bar{k}, s)$, are decreasing with the industry size, $n .{ }^{16}$ If $\alpha=0$, then RJV member firms and non-member firms are identical and earn identical profits. If $\alpha>0$, then non-member firms make higher gross profits than member firms as they enjoy a higher degree of differentiation (less intense competition) in the product market than the member firms. Furthermore, taking the size of the industry as given, non-member firms benefit from a larger size of RJV as the difference in gross profits increases with $\bar{k}$.

Equilibrium degree of cooperation In the first stage of the game, the members of the RJV jointly set $\alpha$, so as to maximize their joint profits, $\bar{k} \Pi_{R}^{*}(\bar{k}, \alpha)$. Since the RJV member firms are symmetric, this program is equivalent to maximizing $\Pi_{R}^{*}(\bar{k}, \alpha)$.

Lemma 1 If $\alpha^{*}>0$, an individual member of the RJV obtains a higher net profit than a nonmember firm.

Proof. RJV member firms are always-at least weakly-better off by cooperating than by not cooperating, as they can set the degree of cooperation $\alpha=0$ and receive the same equilibrium profits as the non-member firms. Therefore, if $\alpha^{*}>0$, it must be that $\Pi_{R}^{*}>\Pi_{-R}^{*}$.

As we noted earlier, for a given degree of differentiation, non-member firms make higher gross profits than members of the RJV. However, in the equilibrium, the savings in product development costs enjoyed by the RJV members can compensate for the loss in gross profits (that is due to a lower degree of differentiation among the member firms' products).

In deciding on the degree of cooperation RJV member firms face the following trade-off. On the one hand, a higher degree of cooperation yields larger economies of development costs (development cost effect). On the other hand, it leads to fiercer competition through reduction in the degree of differentiation between the member firms (competition effect).

In order to study how $\alpha^{*}$ varies with $\bar{k}$, we first determine the effect of an increase in $\bar{k}$ on the equilibrium gross profits.

\footnotetext{
${ }^{16}$ See Appendix A1 for the derivation of equilibrium gross profits.
} 
Lemma 2 Assume that $\alpha>0$. Then, the equilibrium gross profits of the member firms are decreasing with the size of the RJV for $\bar{k}<n / 2+1 /\left(1-s_{\max }\right) \equiv \widetilde{k}$ (and are increasing with it otherwise), whereas the equilibrium gross profits of the non-member firms are increasing with the size of the RJV for all $\bar{k}$.

Proof. See Appendix A2.

The intuition behind Lemma 2 is as follows. When an additional firm participates in the RJV (i.e., the size of the RJV increases from $\bar{k}$ to $\bar{k}+1$ ), the demand for this firm and for the other members shifts inward (as the degree of differentiation between this additional member of the RJV and other $\bar{k}$ members is reduced from $s_{\max }$ to $s(\alpha)$ ), whereas the demand for non-member firms remains unchanged. ${ }^{17}$ Therefore, an increase in the size of the RJV has a negative direct effect on profit for the member firms and no direct effect for the non-member firms. An increase in the size of the RJV also has a positive strategic effect on profits. This is because as the demand for RJV members shifts inward, each RJV member firm reduces its output, which implies a positive effect on other firms' profits.

To summarize, an increase in the size of the RJV implies only a positive strategic effect for the non-member firms, which explains why $\pi_{-R}^{*}$ is increasing with $\bar{k}$. For the members of the RJV, an increase in the size of the RJV creates both a negative direct effect and a positive strategic effect on gross profits.

Proposition 1 The equilibrium degree of cooperation, $\alpha^{*}$, varies non-monotonically with $\bar{k}$.

Proof. See Appendix B.

The relationship between the size of the RJV and the equilibrium degree of cooperation in product development is non-monotonic due to the presence of three effects that determine this relationship: ${ }^{18}$

(i) Development cost effect A higher number of member firms implies larger savings from development costs, which gives member firms an incentive to cooperate more in product development.

\footnotetext{
${ }^{17}$ This is because, by the construction of our model, the degree of differentiation between any given two non-member firms is the same as the degree of differentiation between a given member firm and a non-member firm. The result presented in this Lemma hinges on this "symmetry" property.

${ }^{18}$ See also Appendix C, where we provide three special cases to illustrate how these three effects interact and affect the equilibrium degree of cooperation.
} 
(ii) Negative direct effect and positive strategic effect As Lemma 2 shows, the profit of an RJV member is decreasing with $\bar{k}$ when $\bar{k}$ is small, and increasing with $\bar{k}$ otherwise, due to the negative direct effect and the positive strategic effect. The RJV member firms set a low degree of cooperation when the former effect dominates the latter (and a high degree of cooperation otherwise).

(iii) Sensitivity of profits A larger $\bar{k}$ makes gross profits of the RJV member firms less sensitive to differentiation when the degree of differentiation is low, which in turn gives member firms an incentive to cooperate more in product development. To see why, consider the following two extreme cases. If the degree of differentiation is near zero, a marginal increase in the degree of differentiation yields a significant increase in profits when the number of member firms is small, whereas its impact is negligible when the number of member firms is large (the number of firms has a greater impact on profits than the degree of product differentiation). On the other hand, if $s \rightarrow 1$

(such that each firm serves an almost independent market), a marginal reduction in the degree of differentiation has a small (resp., large) impact on profits if the number of member firms is small (resp., large).

Proposition 2 The equilibrium degree of cooperation, $\alpha^{*}$, increases with $n$ if $s\left(\alpha^{*}\right) \leq \widetilde{s}\left(s_{\max }\right)$, and decreases with $n$ otherwise.

Proof. See Appendix D.

For a given size of RJV, a higher degree of cooperation implies a lower degree of differentiation among the member firms' products, which in turn intensifies competition. A larger number of firms in the industry makes profits less sensitive to differentiation for low degrees of differentiation (and more sensitive to differentiation for high degrees of differentiation). Therefore, when $s$ is sufficiently low, a higher number of industry firms leads to a higher degree of cooperation.

Unfortunately, it is not possible to provide further analysis analytically, and hence, we specify the functional forms and revert to numerical simulations.

\section{Numerical Simulations}

We specify the development cost and the degree of differentiation functions as follows:

$$
d(\alpha)=\frac{\delta}{2} \alpha^{1 / \beta}
$$


and

$$
s(\alpha)=s_{\max }-\left(s_{\max }-s_{\min }\right) \alpha^{\gamma}
$$

with $\beta, \gamma>0$. Note that both functions satisfy our modeling assumptions.

We consider the following ranges for the parameter values: $n \in\{4,5,6, \ldots, 25\} ; \bar{k} \in\{2,3, \ldots, n\}$; $\beta \in\{1,2,3,4\} ; \gamma \in\{1,2,3,4\} ; s_{\max } \in\{0.3,0.4, \ldots, 0.9\} ; s_{\min } \in\left\{0.0,0.1, \ldots, s_{\max }-0.1\right\} ;$ and $\delta \in\left\{0.0,0.2,0.4, \ldots, 2 \pi_{R}^{*}(\alpha=0, \bar{k}=1)\right\}$. For each value of the vector of parameters, we determine $\alpha^{*}$ as the value of $\alpha$ which maximizes the RJV profit for $\alpha \in[0,1]$ and by steps of 0.01 for $\alpha$.

From Proposition 1, we know that $\alpha^{*}(k)$ can take different forms. In what follows, we use a data set of simulations (of size $7,250,896$ ) to estimate the relationship between $\alpha^{*}$ and $\bar{k}^{19}$ To do that, we run an ordinary least squares (OLS) regression, with $\alpha^{*}$ as the dependent variable, and $\bar{k}$ and the other model parameters as the explanatory variables. The results are reported in Table 1 in Appendix E1.

Although the equilibrium degree of cooperation, $\alpha^{*}$, varies non-monotonically with $\bar{k}$, on average, the degree of cooperation is decreasing with the (given) size of the RJV. That is, our simulations show that, on average, RJVs with a large number of firms tend to cooperate on fewer product components than those with fewer number of firms. The equilibrium degree of cooperation also, on average, increases with the total number of firms in the industry as well as the development costs.

\section{An RJV with an endogenous size and an exogenous scope}

In this subsection, we consider an exogenously determined degree of cooperation, $\bar{\alpha}>0$, and study the equilibrium size of an RJV. In particular, we investigate how the equilibrium size of the RJV varies with the degree of cooperation in product development. ${ }^{20}$

We define the equilibrium size of the RJV such that $k^{*}$ satisfies the following conditions: (i) $\Pi_{R}\left(k^{*}, \bar{\alpha}\right) \geq \Pi_{R}\left(k^{*}-1, \bar{\alpha}\right)$; (ii) $\Pi_{R}\left(k^{*}, \bar{\alpha}\right) \geq \Pi_{R}\left(k^{*}+1, \bar{\alpha}\right)$; and (iii) $\Pi_{R}\left(k^{*}, \bar{\alpha}\right) \geq \Pi_{-R}\left(k^{*}-1, \bar{\alpha}\right) .{ }^{21}$

The profit of an RJV member firm is given by

$$
\Pi_{R}^{*}(k, \bar{\alpha})=\pi_{R}^{*}(k, s(\bar{\alpha}))-\left[d(1)-\frac{k-1}{k} d(\bar{\alpha})\right]
$$

\footnotetext{
${ }^{19}$ The programs for the simulations were programmed in $\mathrm{C}$, and are available upon request from the authors.

${ }^{20}$ This is the same approach adopted by Poyago-Theotoky (1995) and Falvey et al. (2006).

${ }^{21}$ One can think of cases where first an RJV is formed, and then the member firms decide on the degree of cooperation. Conditions (i) and (ii) state that all members of the RJV have no incentive to accept a firm as an additional member or to exclude it, given that the equilibrium degree of cooperation will be determined by the size of the RJV. Condition (iii) implies that none of the RJV members has an incentive to leave the RJV unilaterally.
} 
Proposition 3 Recall that $\widetilde{k} \equiv n / 2+1 /\left(1-s_{\max }\right)$, which is defined in Lemma 2 , and assume that an equilibrium exists. If $\widetilde{k}<n$, then the equilibrium size of the $R J V$ is either (i) $n$, or (ii) smaller than $\tilde{k}$.

Proof. Let us assume for the moment that $k$ is a real number, and not an integer. We have

$$
\frac{d \Pi_{R}^{*}(k, \bar{\alpha})}{d k}=\frac{d \pi_{R}^{*}(k, s(\bar{\alpha}))}{d k}+\frac{d(\bar{\alpha})}{k^{2}} .
$$

The first term is positive if $k>\widetilde{k}$, and negative otherwise, and the second term is always positive. Therefore, if there is an equilibrium, we either have a corner solution, i.e., $k^{*}=n$, or $k^{*}<\widetilde{k}$.

This result implies that if $n$ is sufficiently high so that $\widetilde{k} \simeq n / 2$, then the equilibrium RJV involves either all firms $\left(k^{*}=n\right)$ or less than half of the firms in the industry $\left(k^{*}<n / 2\right)$. Another consequence is that we can have multiple equilibria, ${ }^{22}$ one of which involves an industry-wide RJV, and another, which involves an RJV with (approximately) less than half of the firms in the industry. ${ }^{23}$

We now would like to study the variation of the equilibrium size of the RJV with the degree of cooperation. Assume for the purpose of this analysis that $k$ is a real number. Since the equilibrium size of the RJV maximizes the joint profits of the members (this corresponds to conditions (i) and (ii) in the definition of the equilibrium), the equilibrium size solves the first order condition,

$$
\frac{d \pi_{R}^{*}(k, s(\bar{\alpha}))}{d k}+\frac{d(\bar{\alpha})}{k^{2}}=0
$$

This first order condition defines implicitly a function $k^{*}(\bar{\alpha})$. Given that the second order condition holds, from the implicit function theorem, the variations of $k^{*}(\bar{\alpha})$ with respect to $\bar{\alpha}$ are given by the variations of the two terms in $(4)$ with respect to $\bar{\alpha}$. Since $d^{\prime}(\bar{\alpha})>0$, the second term increases with $\bar{\alpha}$, which tends to increase $k^{*}(\bar{\alpha})$. The intuition is that a higher degree of cooperation implies higher savings from development costs, which tends to increase the size of the RJV.

However, the first term can either increase or decrease with $\alpha$, as

$$
\frac{d}{d \bar{\alpha}}\left[\frac{d \pi_{R}^{*}(k, s(\bar{\alpha}))}{d k}\right]=\frac{\partial}{\partial s}\left[\frac{d \pi_{R}^{*}(k, s)}{d k}\right] \frac{\partial s(\bar{\alpha})}{\partial \bar{\alpha}}
$$

\footnotetext{
${ }^{22}$ Here, we mean in terms of the size of the RJV. Naturally, given an equilibrium size of the RJV, $k^{*}$, and the number of firms in the industry, $N$, there are $\left(\begin{array}{c}N \\ k^{*}\end{array}\right)$ equilibria.

${ }^{23}$ Note that, depending on the parameter values, there may be no equilibria as well.
} 
and $\partial\left[d \pi_{R}^{*} / d k\right] / \partial s$ can be either positive or negative (we always have $\partial s(\bar{\alpha}) / \partial \bar{\alpha}<0$ ). Indeed, intuitively, a lower $s$ implies a higher magnitude both for the negative direct effect and the positive strategic effect. Therefore, not surprisingly, a higher $s$ can lead either to a higher or a lower $d \pi_{R}^{*} / d k$. This means that the effect of $\alpha$ through the direct and the strategic effects tends either to increase or to decrease the size of the RJV.

The overall effect of a higher $\alpha$ on the equilibrium size of the RJV, $k^{*}$, depends ultimately on $s(\cdot)$ and $d(\cdot)$. Since we cannot establish an analytical result on the overall effect of the degree of cooperation on the equilibrium size of the RJV with the general forms for $s(\cdot)$ and $d(\cdot)$, we now specify them and revert to numerical simulations.

\section{Numerical Simulations}

We use the same functions for the development cost and the degree of differentiation as in the previous section, and we run our simulations for the following ranges for parameter values: $n \in$ $\{4,5,6, \ldots, 25\} ; \beta \in\{1,2,3,4\} ; \gamma \in\{1,2,3,4\} ; s_{\max } \in\{0.3,0.4, \ldots, 0.9\} ; s_{\min } \in\left\{0.0,0.1, \ldots, s_{\max }-0.1\right\} ;$ $\delta \in\left\{0.0,0.2,0.4, \ldots, 2 \pi_{R}^{*}(\alpha=0, k=1)\right\}$; and $\bar{\alpha} \in\{0.00,0.05,0.10, \ldots, 1.00\}$. For each value of the vector of parameters, we determine $k^{*}$ as follows: (i) we first determine the set of values of $k \in\{2,3, \ldots, n\}$ that satisfy the three conditions of the equilibrium; and (ii) in cases with multiple equilibria, we select the equilibrium which provides the RJV with the highest profit. ${ }^{24}$

The OLS estimation results (with $k^{*}$ as the dependent variable, and with $N=14,369,280$ ) can be found in Table 2 in Appendix E2. Similar to the previous section, on average, there is a negative relationship between the scope and the size of the RJV. A higher degree of cooperation, on average, implies a lower equilibrium number of RJV member firms. Additionally, we find that, on average, higher development costs are associated with RJVs with a higher number of firms.

\section{An RJV with an endogenous size and an endogenous scope}

In this subsection, we consider an RJV with an endogenous size and an endogenous degree of cooperation.

Let $\widetilde{\alpha}^{*}(k)=\arg \max \left\{\Pi_{R}(k, \alpha)\right\}$, where $\Pi_{R}(k, \alpha)$ is given by (3). We define the equilibrium such that $\left\{k^{*}, \alpha^{*}\right\}$ satisfy the following conditions: (i) $\Pi_{R}\left(k^{*}, \alpha^{*}\right) \geq \Pi_{R}\left(k^{*}-1, \widetilde{\alpha}^{*}\left(k^{*}-1\right)\right)$; (ii)

\footnotetext{
${ }^{24}$ We have $k^{*}=1$ if no RJV is formed in equilibrium.
} 
$\Pi_{R}\left(k^{*}, \alpha^{*}\right) \geq \Pi_{R}\left(k^{*}+1, \widetilde{\alpha}^{*}\left(k^{*}+1\right)\right)$; (iii) $\Pi_{R}\left(k^{*}, \alpha^{*}\right) \geq \Pi_{-R}\left(k^{*}-1, \widetilde{\alpha}^{*}\left(k^{*}-1\right)\right)$; and (iv) $\alpha^{*}=$ $\widetilde{\alpha}^{*}\left(k^{*}\right)$.

In what follows, we study the variation of $k^{*}$ and $\alpha^{*}$ with the number of firms, $n$.

First, consider the case where the degree of cooperation has an insignificant impact on product differentiation (this is the case if $s_{\min } \simeq s_{\max }$ ). In this case, a higher degree of cooperation means larger benefits to the member firms (through cost-sharing), and hence, RJV members set the highest degree of cooperation in product development, (i.e., $\alpha^{*}=1$ ). Furthermore, adding additional members to the RJV has an insignificant negative effect, while profits further increase due to the additional member that contributes to the development cost. Therefore, in equilibrium, there is an industry-wide RJV $\left(k^{*}=n\right),{ }^{25}$ and full cooperation $\left(\alpha^{*}=1\right)$.

Second, consider that $s_{\max }>s_{\min }$. Since we cannot characterize the equilibria analytically for this case, we revert to numerical simulations.

\section{Numerical Simulations}

We consider the same functional forms as in the previous simulations, and also the same range of parameter values. Note that, different from the previous section, $\alpha$ is now determined endogenously. For each value of the vector of parameters, and for each $k \in\{1,2, \ldots, n\}$ we determine an $\alpha^{*}(k)$. We proceed as follows: we determine the value of $\alpha$ which maximizes the RJV profit, for $\alpha \in[0,1]$ and by steps of 0.01 for $\alpha$. Then, in order to determine $k^{*}$, we (i) first determine the set of values of $k \in\{2,3, \ldots, n\}$ that satisfy the three conditions of the equilibrium, and (ii) in cases with multiple equilibria, we select the equilibrium which provides the RJV with the highest profit.

Similar to the previous section, we use our simulated data, this time to estimate the relationship between $k^{*}$ and $\alpha^{*}$. The estimation results are reported in Table 3 and can be found in Appendix E3. We find a positive relationship between the equilibrium size of the RJV and the equilibrium degree of cooperation. Also, on average, both the equilibrium size of the RJV and the equilibrium degree of cooperation are increasing with the industry size. This implies that, on average, in industries with a large number of firms, RJVs tend to include a large number of firms that cooperate on a relatively large number of product components. Product development costs, on average, also increase both the size and the scope of the RJV.

\footnotetext{
${ }^{25}$ Indeed, when $s$ goes to $s_{\max }^{-}$, we find that $\frac{\partial}{\partial k} \pi_{R}^{*}$ goes to $d(\alpha) / k^{2}$, hence, $\partial \pi_{R}^{*} / \partial k>0$, which implies that $k^{*}=N$.
} 


\section{Social welfare}

In this section, we compare how the size and the scope of the RJV compare to the social optima in the three cases we have studied. We show that in all three cases, the equilibrium size and scope of the RJV do not coincide with the social optimum. We also discuss the economic effects that explain this divergence.

Social welfare is defined as the sum of industry profit and consumer surplus. Hence, for a given $k$ and a given $\alpha$, we have

$$
W=k \Pi_{R}(k, \alpha)+(n-k) \Pi_{-R}(k, \alpha)+C S,
$$

where $\Pi_{R}(k, \alpha), \Pi_{-R}(k, \alpha)$, and $C S$ can be found in Appendix F.

An RJV with an exogenous size and an endogenous scope In this case, to determine whether $\alpha^{*}$ is too low or too high compared to the social optimum, we compute

$$
\left.\frac{d W}{d \alpha}\right|_{\alpha=\alpha^{*}}=\left.(n-\bar{k}) \frac{d \Pi_{-R}(\bar{k}, \alpha)}{d \alpha}\right|_{\alpha=\alpha^{*}}+\left.\frac{d C S}{d \alpha}\right|_{\alpha=\alpha^{*}} .
$$

We have

$$
\frac{d C S}{d \alpha}=\frac{\partial C S}{\partial s} \frac{\partial s}{\partial \alpha}
$$

and we find that $\partial C S / \partial s>0 .{ }^{26}$ Therefore, $d C S / d \alpha<0$, which means that the consumer surplus is decreasing with the degree of cooperation. Therefore, from the consumers' point of view, the equilibrium degree of cooperation is too high. This is because consumers value variety and a higher degree of cooperation reduces the degree of differentiation among the RJV member firms. Under Cournot competition, the reduction in the prices (due to more intense competition) does not compensate for the consumer's utility loss from reduced differentiation.

Additionally, we have

$$
\frac{d \Pi_{-R}(\bar{k}, \alpha)}{d \alpha}=\frac{\partial \Pi_{-R}}{\partial s} \frac{\partial s}{\partial \alpha}
$$

and we find that

$$
\frac{\partial \Pi_{-R}}{\partial s}=\frac{-2(\bar{k}-1)(a-c)^{2}\left(1+s_{\max }\right)\left(1-s_{\max }\right) \bar{k}\left(1+s+\bar{k}\left(s_{\max }-s\right)\right)}{\left((1+s)\left((n-1)\left(1-s_{\max }\right)+2\right)+\bar{k}\left(s_{\max }-s\right)\left((n-\bar{k})\left(1-s_{\max }\right)+2\right)\right)^{3}} .
$$

\footnotetext{
${ }^{26}$ The proof is done under Mathematica, and the mathematica file is available upon request from the authors.
} 
Since the numerator is negative and the denominator is positive, then $\partial \Pi_{-R} / \partial s<0$, and hence, $d \Pi_{-R}(\bar{k}, \alpha) / d \alpha>0$. That is, the non-member firms' profits are increasing with the degree of cooperation. This is because a higher degree of cooperation implies a lower output produced by the RJV member firms (as a reaction to the reduced degree of differentiation), which benefits the nonmember firms. Therefore, the equilibrium degree of cooperation is too low from the non-members' point of view. This also implies that it is too low from the industry point of view, unless all firms are included in the RJV.

To summarize, whether $\alpha^{*}$ is too low or too high compared to the social optimum is a priori ambiguous.

We, therefore, ran our simulations for the same functional forms and parameter values mentioned above. If $\bar{k}=n$ (industry-wide cooperation), we find that the degree of cooperation is always too high. This is in line with our analysis: with industry-wide cooperation, the degree of cooperation is suboptimally high (resp., low) if it is too high (resp., low) from the consumer viewpoint. Since consumer surplus is decreasing with the degree of cooperation, then the equilibrium degree of cooperation is always too high from a social welfare perspective.

If $\bar{k}<n$, we find that $\alpha^{*}$ can be either too low or too high compared to the social optimum, $\alpha^{w}$. We conducted a probit estimation on the probability that $\alpha^{*}>\alpha^{w}$. The estimation results show that $\alpha^{*}$ is more likely to be too high when $n$ is high and $k / n$ is high, that is, for large industries and RJVs of a large relative size. It might be more relevant to study the absolute difference between $\alpha^{*}$ and $\alpha^{w}$ to determine whether the equilibrium is "far" from the social optimum. We, therefore, regressed $\left|\alpha^{*}-\alpha^{w}\right|$ with respect to $k / n, n$, and our other simulation parameters. The results show that the equilibrium is farther from the social optimum when $n$ is higher and $k / n$ is lower.

An RJV with an endogenous size and an exogenous scope In this case, in order to determine how $k^{*}$ compares with the social optimum, we assume that $k$ is a real number, and compute the following:

$$
\left.\frac{d W}{d k}\right|_{k=k^{*}}=\left.(n-k) \frac{d \Pi_{-R}(k, \bar{\alpha})}{d k}\right|_{k=k^{*}}+\left.\frac{d C S}{d k}\right|_{k=k^{*}} .
$$

From Lemma 2, we know that $d \Pi_{-R}(k, \bar{\alpha}) / d k>0$. That is, from the non-member RJV firms' point of view, the equilibrium size of the RJV is too small. This also implies that the size of the RJV that maximizes the industry profits is necessarily larger than the equilibrium size (since $k^{*}$ maximizes the RJV member firms' profits), unless all firms are included in the RJV. This is because 
when a non-member firm joins the RJV, it-as well as other member firms-contracts output (due to the reduced degree of differentiation), which benefits the remaining non-member firms in the industry.

We also find that $d C S / d k<0,{ }^{27}$ which means that consumers would be better off with a smaller size RJV. This is because, consumers value variety, and the degree of differentiation among the RJV members is less than the degree of differentiation among non-member firms (which is the same as the degree of differentiation between any member firm and any non-member firm).

As a result, how $k^{*}$ compares to the social optimum is a priori ambiguous.

We ran our simulations for the same functional forms and parameter values mentioned above. We find that the equilibrium size of the RJV can be either too high or too low. We define a dummy variable that takes value 1 if $k^{*}>k^{w}$, and value 0 otherwise. We then estimate a probit model with this dummy variable as the dependent variable and our model parameters as explanatory variables. We find that the size of the RJV is more likely to be too high from a welfare point of view if (i) $\bar{\alpha}$ is high, and (ii) $n$ is high. Finally, we regressed (with an OLS regression) $\left|k^{*}-k^{w}\right|$ on our model parameters. We find that the equilibrium is farther from the social optimum when (i) $\bar{\alpha}$ is high, and (ii) $n$ is high.

An RJV with an endogenous size and an endogenous scope We find that the equilibrium size and scope of the RJV can be too high or too low from a social welfare point of view. To determine the market conditions under which the equilibrium is the "farthest" from the social optimum, we regressed $\left|k^{*}-k^{w}\right|$ and $\left|\alpha^{*}-\alpha^{w}\right|$ on our model parameters, where $k^{w}$ and $\alpha^{w}$ are the socially optimum size of the RJV and scope of the RJV, respectively. We find that, ceteris paribus, $\left|k^{*}-k^{w}\right|$ and $\left|\alpha^{*}-\alpha^{w}\right|$ are higher (that is, the size and scope of the RJV are farther from the social optimum) when (i) the industry size $(n)$ is larger, (ii) the development cost $(\delta)$ is higher, and (iii) $s_{\min }$ is higher and $s_{\max }$ is lower.

An interesting question is also whether the RJV also has too wide of a scope when the RJV is too large (for instance). To answer this equation, we regressed $\left|k^{*}-k^{w}\right|$ on $\left|\alpha^{*}-\alpha^{w}\right|$ and on our other model parameters. We find a positive a significant relationship between $\left|k^{*}-k^{w}\right|$ on $\left|\alpha^{*}-\alpha^{w}\right|$, that is, when an RJV is too large in size from a welfare point of view, it also tends to have too large a scope.

\footnotetext{
${ }^{27}$ The proof is done under Mathematica, and the mathematica file is available upon request from the authors.
} 


\section{Conclusion}

In this paper, we have provided a model of RJV in product development in an oligopolistic setting to study the size and the scope of RJV.

The relationship between the size and the scope of an RJV proves to be rather complex. Even for the cases where either the size or the scope of an RJV is given, the relationship between the two can be non-monotonic. However, our numerical simulations reveal that, on average, there is a negative relationship between the two when either one is exogenously determined. When both the size and the scope of the RJV are endogenous, we find that, on average, there is a positive relationship between the equilibrium size and the equilibrium scope. Furthermore, both the size and the scope of an RJV tend to increase with the industry size.

In our attempt to describe the relationship between the size of an RJV and the degree of cooperation in product development, we adopted the simplest setting possible. In particular, we considered a single RJV within an industry. We also ignored any uncertainty or spillovers that the product development process may involve. These are possible areas for possible extensions.

\section{References}

Bourreau, M. and Doğan, P., 2010. Cooperation in product development and process R\&D between competitors. International Journal of Industrial Organization, Vol. 28(2), pp. 176-190.

Cabral, L. M. B, 2000. R\&D Cooperation and Product Market Competition. International Journal of Industrial Organization, Vol. 18(7), pp. 1033-47.

Choi, J. P., 1993. Cooperative R\&D with Product Market Competition. International Journal of Industrial Organization, Vol. 11(4), pp. 553-71.

Clark, K.B., Chew, W.B. and Fujimoto,T., 1987. Product Development in the World Auto Industry. Brooking Papers on Economic Activity, Vol. 3, pp. 729-71.

d'Aspremont, C. and Jacquemin, A., 1988. Cooperative and Noncooperative R\&D in Duopoly with Spillovers. American Economic Review, Vol. 78(5), pp. 1133-37.

d'Aspremont, C. and Jacquemin, A., 1990. Erratum. American Economic Review, Vol. 80, 1990, pp. $641-42$. 
Dixit, A., 1979. A Model of Duopoly Suggesting a Theory of Entry Barriers. Bell Journal of Economics, Vol. 10, pp. 20-32.

Falvey, R., Poyago-Theotoky, J. and Teerasuwannajak, K., 2006. Coordination Costs: A Drawback for Research Joint Ventures? Working Paper, Loughborough University.

Goyal, S., Moraga-González, J.L. and Konovalov, A., 2008. Hybrid R\&D, Journal of the European Economic Association, Vol. 6(6), pp. 1309-38.

Kamien, M. I., Muller, E., and Zang, I., 1992. Research Joint Ventures and R\&D Cartels. American Economic Review, Vol. 82(5), pp. 1293-306.

Kamien, M. I. and Zang, I., 2000. Meet me halfway: research joint ventures and absorptive capacity. International Journal of Industrial Organization, Vol. 18, pp. 995-1012.

Katz, M. L., 1986. An Analysis of Cooperative Research and Development. Rand Journal of Economics, Vol 17(4), pp. 527-43.

Lado, N., Licandro, O. and Perez F., 2004. How brand names affect the price setting of carmakers producing twin cars? Economics Working Papers ECO2004/01, European University Institute.

Lambertini, L., Poddar, S., and Sasaki, D., 2002. Research Joint Ventures, Product Differentiation, and Price Collusion. International Journal of Industrial Organization, Vol. 20(6), pp. 829-54.

Lin, P. and Saggi, K., 2002. Product Differentiation, Process R\&D, and the Nature of Market Competition. European Economic Review, Vol. 46(1), pp. 201-11.

Martin, S., 1996. R\&D joint ventures and tacit product market collusion. European Journal of Political Economy, Vol. 11(4), pp. 733-41.

Poyago-Theotoky, J., 1995. Equilibrium and Optimal Size of a Research Joint Venture in an Oligopoly with Spillovers, Journal of Industrial Economics, Vol. 43(2), pp. 209-26.

Röller, L.-H., Siebert, R. and Tombak M.M., 2007. Why Firms Form (or do not Form) RJVs. The Economic Journal. Vol. 117(522), pp. 1122-44.

Singh, N., Vives, X., 1984. Price and Quantity Competition in a Differentiated Duopoly. RAND Journal of Economics, Vol. 15, pp. 546-54. 
Sullivan. M.W., 1998, How brand names affect the demand for twin automobiles. Journal of Marketing Research, Vol. 35, pp. 154-65.

Suzumura, K., 1992. Cooperative and Noncooperative R\&D in an Oligopoly with Spillovers. American Economic Review, Vol. 82(5), pp. 1307-20.

Vilasuso, J. and Frascatore, M. R., 2000. Public Policy and R\&D When Research Joint Ventures Are Costly. Canadian Journal of Economics, Vol. 33(3), pp. 818-39. 


\section{Appendix}

\section{A. An RJV with an exogenous size and an endogenous scope}

\section{A1. Equilibrium profits}

The profit of firm $i=1 \ldots n$ is equal to $\pi_{i}=\left(p_{i}-c\right) q_{i}$. Each firm chooses its quantity, $q_{i}$, so as to maximize its profit. The first-order condition for profit maximization is

$$
p_{i}-c+q_{i} \frac{d p_{i}}{d q_{i}}=p_{i}-c-q_{i}=0
$$

that is $p_{i}-c=q_{i}$. We search for a symmetric equilibrium, such that in equilibrium $q_{1}=\ldots=q_{k}$ for member firms and $q_{k+1}=\ldots=q_{n}$ for non-member firms. Using the first-order conditions and the symmetry conditions, we find:

$$
\pi_{R}^{*}=\left(q_{R}^{*}\right)^{2}=\frac{\left(1+s_{\max }\right)^{2}(a-c)^{2}}{\left((1+s)\left((n-1)\left(1-s_{\max }\right)+2\right)+k\left(s_{\max }-s\right)\left((n-k)\left(1-s_{\max }\right)+2\right)\right)^{2}}
$$

for the RJV member firms; and

$$
\pi_{-R}^{*}=\left(q_{-R}^{*}\right)^{2}=\frac{\left(1+s+k\left(s_{\max }-s\right)\right)^{2}(a-c)^{2}}{\left((1+s)\left((n-1)\left(1-s_{\max }\right)+2\right)+k\left(s_{\max }-s\right)\left((n-k)\left(1-s_{\max }\right)+2\right)\right)^{2}}
$$

for the non-member firms.

\section{A2. Proof of Lemma 2}

Proof. For the first part of the Lemma, notice that the numerator of $\pi_{R}^{*}$ does not depend on $\bar{k}$, and the denominator is increasing with $\bar{k}$ if $2+(2 \bar{k}-n)\left(1-s_{\max }\right)<0$, that is, if $\bar{k}<\widetilde{k}$. For the second part of the Lemma, note that we have $\pi_{-R}^{*}$ increasing with $\bar{k}$ as

$\frac{\partial \pi_{-R}^{*}}{\partial \bar{k}}=\frac{2\left(s_{\max }-s\right)\left(1-s_{\max }\right)(a-c)^{2}\left(1+s+\left(s_{\max }-s\right) \bar{k}\right)\left[\bar{k}^{2}\left(s_{\max }-s\right)+(1+s)(2 \bar{k}-1)\right]}{\left((1+s)\left((n-1)\left(1-s_{\max }\right)+2\right)+\bar{k}\left(s_{\max }-s\right)\left((n-\bar{k})\left(1-s_{\max }\right)+2\right)\right)^{3}}>0$

since both the both numerator and denominator are positive.

\section{B. Proof of Proposition 1}

Proof. The equilibrium degree of cooperation, $\alpha^{*}$, satisfies the following first-order condition 


$$
\frac{\partial \pi_{R}^{*}}{\partial s} \frac{\partial s}{\partial \alpha}+\frac{\bar{k}-1}{\bar{k}} \frac{\partial d}{\partial \alpha}=0
$$

This condition defines implicitly a function $\alpha^{*}(\bar{k})$. Assuming that the second-order holds strictly, by the implicit function theorem, the variations of $\alpha^{*}(\bar{k})$ are given by the variations of the left-hand of (A1) with respect to $\bar{k}$. First, we have

$$
\frac{\bar{k}-1}{\bar{k}} \frac{\partial d}{\partial \alpha}
$$

increasing with $\bar{k}$. This is the development cost effect; a higher $\bar{k}$ implies higher savings from development costs, which tends to increase the degree of cooperation. Second, we have

$$
\frac{\partial}{\partial \bar{k}} \frac{\partial \pi_{R}^{*}}{\partial s}=\frac{2(a-c)^{2}\left(1+s_{\max }\right)^{2}\left[\left(1-s_{\max }\right)(n-2 \bar{k})+2\right] T\left(\bar{k}, n, s, s_{\max }\right)}{\left((1+s)\left((n-1)\left(1-s_{\max }\right)+2\right)+\bar{k}\left(s_{\max }-s\right)\left((n-\bar{k})\left(1-s_{\max }\right)+2\right)\right)^{4}},
$$

where

$$
T=2\left(1-s_{\max }\right)\left(s_{\max }-s\right) \bar{k}^{2}-2\left(2+\left(1-s_{\max }\right) n\right)\left(s_{\max }-s\right) \bar{k}+\chi
$$

and

$$
\chi=\left(1+3 s_{\max }-2 s\right)\left(1+s_{\max }+n\left(1-s_{\max }\right)\right)>0 .
$$

$T$ is a second-degree polynomial in $\bar{k}$. Assume that $T=0$ has two solutions, $k_{1}$ and $k_{2}$. We know that $k_{1} k_{2}$ has the sign of $2\left(1-s_{\max }\right)\left(s_{\max }-s\right) \chi$, hence, it is positive. Therefore, if $T$ has two roots, either they are both negative or both positive. It follows that either $T$ is always positive or $T$ is first positive, then negative, then positive. If $T$ is positive, then (A2) has the sign of $\left(1-s_{\max }\right)(n-2 \bar{k})+2$, whereas, if $T$ is negative, then (A2) has the opposite sign. It follows that the equilibrium degree of cooperation varies non-monotonically with $\bar{k}$.

\section{The relationship between $\alpha^{*}$ and $\bar{k}$}

We provide three special cases to illustrate how the three effects that determine the relationship between $\alpha^{*}$ and $\bar{k}$.

Case 1. $\partial s / \partial \alpha=0$. In this case, only the positive development cost effect is at work. Therefore, firms choose $\alpha^{*}=1$ (full cooperation), for any $\bar{k}$.

Case 2. $s$ approaches $s_{\max }^{-}$. In this case, we find that $\partial\left(\partial \pi_{R}^{*} / \partial s\right) / \partial \bar{k}$ has the sign of $2+$ $\left(1-s_{\max }\right)(n-2 \bar{k})$. This is because the sensitivity of the profits effect is always positive, and the 
sign of the competition effect depends on whether the negative direct effect or the positive strategic effect dominates. Consequently, the competition effect is negative (giving incentives to reduce $\alpha^{*}$ ) when $\bar{k}<\widetilde{k}$, and positive otherwise. It follows that when $\bar{k}<\widetilde{k}$, we have $\alpha^{*}$ decreasing with $\bar{k}$ if the negative competition effect dominates the positive development cost effect, and increasing otherwise. When $\bar{k} \geq \widetilde{k}$, both effects move in the same direction and $\alpha^{*}$ is increasing with $\bar{k}$.

Case 3. $s_{\max }=1$. In this case, the RJV profit effect is always positive (i.e., $\pi_{R}^{*}$ is decreasing with $\bar{k}$ for all $\bar{k}$ ). Therefore, the sign of the competition effect is given by the sign of the sensitivity of profits effect; it is positive if $\bar{k}<(2-s) /(1-s)$, and negative otherwise. Therefore, if this inequality holds, the competition effect is negative (which tends to reduce $\alpha^{*}$ ), whereas the development cost effect is positive (which tends to increase $\alpha^{*}$ ). Otherwise, (i.e., $\bar{k}>(2-s) /(1-s)$ ) $\alpha^{*}$ is increasing with $\bar{k}$.

\section{Proof of Proposition 2}

Proof. Let us assume that $\alpha^{*}$ is an interior solution. If this is the case, then $\alpha^{*}$ satisfies the first-order condition

$$
\frac{d \Pi_{R}}{d \alpha}-\frac{d D_{R}}{d \alpha}=0
$$

Given that the second-order condition holds, the variation of $\alpha^{*}$ with respect to $n$ are given by the variation of the left side of the FOC. Since $d D_{R} / d \alpha$ does not depend on $n$, then the variation of $\alpha^{*}$ with respect to $n$ is given by the variation of $d \Pi_{R} / d \alpha$ with respect to $n$. We have

$$
\frac{d \Pi_{R}}{d \alpha}=\frac{\partial \Pi_{R}}{\partial s} \frac{\partial s}{\partial \alpha}
$$

We compute

$$
\frac{\partial}{\partial n}\left[\frac{\partial \Pi_{R}}{\partial s}\right]=\frac{A}{B^{4}}
$$

where $A=2(a-c)^{2}(\bar{k}-1)\left(1-s_{\max }\right)\left(1+s_{\max }\right)^{2} C$ has the sign of $C$. We find that $C \geq 0$ if and only if $s \geq \widetilde{s}\left(s_{\max }\right)$, with

$$
\widetilde{s}\left(s_{\max }\right)=\frac{2+2 n-3 \bar{k}-2\left(\bar{k}^{2}-1+n-\bar{k}(2+n)\right) s_{\max }+\bar{k}(3+2 \bar{k}-2 n) s_{\max }^{2}}{2(\bar{k}-1)\left(1+s_{\max }+(n-\bar{k})\left(1-s_{\max }\right)\right)} .
$$

Therefore, if $s \leq \widetilde{s}\left(s_{\max }\right)$ then $C \leq 0$, hence, $\partial \Pi_{R} / \partial s$ decreases with $n$, and therefore, $\alpha^{*}$ increases with $n$ (since $\partial s / \partial \alpha<0)$. 
Notice that a necessary condition for $s \geq \widetilde{s}\left(s_{\max }\right)$ to happen is $\widetilde{s}\left(s_{\max }\right)<s_{\max }$; that is, we have $\widetilde{s}\left(s_{\max }\right)=s_{\max }$ if and only if

$$
s_{\max }=1-\frac{4}{2+3 \bar{k}-2 n}
$$

\section{E. Estimation Results}

\section{E1. Regression of $\alpha^{*}$}

Column (1) gives the estimation results of an OLS regression of $\alpha^{*}$ on $\bar{k}$ and the other model parameters. Column (2) adds a quadratic term for $\bar{k}$ as a robustness check.

\begin{tabular}{|c|c|c|c|c|}
\hline \multicolumn{5}{|c|}{ Table 1} \\
\hline & \multicolumn{2}{|c|}{ (1) } & \multicolumn{2}{|r|}{$(2)$} \\
\hline & \multicolumn{2}{|c|}{$\alpha^{*}$} & \multicolumn{2}{|r|}{$\alpha^{*}$} \\
\hline $\bar{k}$ & -0.0069 & $(0.00001)$ & -0.0204 & $(0.00004)$ \\
\hline $\bar{k}^{2}$ & & & 0.0006 & $(0.00000)$ \\
\hline$n$ & 0.0053 & $(0.00001)$ & 0.0052 & $(0.00001)$ \\
\hline$s_{\min }$ & 0.3856 & $(0.00025)$ & 0.3856 & $(0.00025)$ \\
\hline$s_{\max }$ & -0.7230 & $(0.00047)$ & -0.7152 & $(0.00047)$ \\
\hline$\delta$ & 0.0166 & $(0.00001)$ & 0.0163 & $(0.00001)$ \\
\hline$\beta$ & -0.0325 & $(0.00005)$ & -0.0325 & $(0.00005)$ \\
\hline$\gamma$ & 0.0778 & $(0.00005)$ & 0.0778 & $(0.00005)$ \\
\hline constant & 0.4384 & $(0.00038)$ & 0.4867 & $(0.00040)$ \\
\hline$R^{2}$ & \multicolumn{2}{|c|}{0.5248} & \multicolumn{2}{|c|}{0.5325} \\
\hline$N$ & \multicolumn{2}{|c|}{$7,250,896$} & \multicolumn{2}{|c|}{$7,250,896$} \\
\hline
\end{tabular}

Standard errors in parentheses.

All coefficients are statistically significant at the $1 \%$ level.

\section{E2. Regression of $k^{*}$}

Column (1) gives the estimation results of an OLS regression of $k^{*}$ on $\bar{\alpha}$ and the other model parameters. Column (2) adds a quadratic term for $\bar{\alpha}$ as a robustness check. 


\begin{tabular}{|c|c|c|c|c|}
\hline \multicolumn{5}{|c|}{ Table 2} \\
\hline & \multicolumn{2}{|c|}{ (1) } & \multicolumn{2}{|r|}{$(2)$} \\
\hline & \multicolumn{2}{|c|}{$k^{*}$} & \multicolumn{2}{|r|}{$k^{*}$} \\
\hline $\bar{\alpha}$ & -6.1731 & $(0.00323)$ & -4.5994 & $(0.01235)$ \\
\hline $\bar{\alpha}^{2}$ & & & -1.6565 & $(0.01255)$ \\
\hline$n$ & 0.2303 & $(0.00018)$ & 0.2303 & $(0.00018)$ \\
\hline$s_{\min }$ & 3.7084 & $(0.00412)$ & 3.7084 & $(0.00412)$ \\
\hline$s_{\max }$ & -6.2249 & $(0.00723)$ & -6.2249 & $(0.00722)$ \\
\hline$\delta$ & 0.1132 & $(0.00016)$ & 0.1132 & $(0.00016)$ \\
\hline$\beta$ & 0.3146 & $(0.00083)$ & 0.3146 & $(0.00083)$ \\
\hline$\gamma$ & 1.3192 & $(0.00083)$ & 1.3192 & $(0.00083)$ \\
\hline constant & 2.9581 & $(0.00587)$ & 2.7220 & $(0.00613)$ \\
\hline$R^{2}$ & \multicolumn{2}{|c|}{0.3793} & \multicolumn{2}{|r|}{0.3801} \\
\hline$N$ & \multicolumn{2}{|c|}{$14,369,280$} & \multicolumn{2}{|c|}{$14,369,280$} \\
\hline
\end{tabular}

Standard errors in parentheses.

All coefficients are statistically significant at the $1 \%$ level.

\section{E3. Regression of $k^{*}$ and $\alpha^{*}$}

Column (1) gives the estimation results of an OLS regression of $k^{*}$ on the model parameters. Column (2) gives the estimation results of a regression with $\alpha^{*}$ as the dependent variable. Finally, column (3) regresses $k^{*}$ on $\alpha^{*}$ and the other model parameters. 
Table 3

\begin{tabular}{|c|c|c|c|c|c|c|}
\hline & \multicolumn{2}{|c|}{ (1) } & \multicolumn{2}{|c|}{$(2)$} & \multicolumn{2}{|r|}{$(3)$} \\
\hline & \multicolumn{2}{|c|}{$k^{*}$} & \multicolumn{2}{|c|}{$\alpha^{*}$} & \multicolumn{2}{|r|}{$k^{*}$} \\
\hline$\alpha^{*}$ & & & & & 0.6035 & $(0.02628)$ \\
\hline$n$ & 0.7460 & $(0.00384)$ & 0.0116 & $(0.00017)$ & 0.7390 & $(0.00385)$ \\
\hline$n^{2}$ & -0.0117 & $(0.00014)$ & -0.0002 & $(0.00006)$ & -0.0116 & $(0.00014)$ \\
\hline$\delta$ & 0.0007 & $(0.00079)$ & 0.0162 & $(0.00004)$ & -0.0090 & $(0.00089)$ \\
\hline$s_{\min }$ & 0.3113 & $(0.02053)$ & 0.4613 & $(0.00092)$ & 0.0329 & $(0.02384)$ \\
\hline$s_{\max }$ & -0.6644 & $(0.03633)$ & -0.7592 & $(0.00163)$ & -0.2061 & $(0.04144)$ \\
\hline$\gamma$ & 2.0234 & $(0.00415)$ & 0.0549 & $(0.00019)$ & 1.9902 & $(0.00439)$ \\
\hline$\beta$ & 1.8750 & $(0.00415)$ & -0.0597 & $(0.00019)$ & 1.9111 & $(0.00443)$ \\
\hline constant & -8.4385 & $(0.03293)$ & 0.4918 & $(0.00148)$ & -8.7353 & $(0.03537)$ \\
\hline$R^{2}$ & \multicolumn{2}{|c|}{0.5172} & \multicolumn{2}{|c|}{0.4879} & \multicolumn{2}{|r|}{0.5176} \\
\hline$N$ & \multicolumn{2}{|c|}{718,464} & \multicolumn{2}{|c|}{718,464} & \multicolumn{2}{|c|}{718,464} \\
\hline
\end{tabular}

Standard errors in parentheses.

All coefficients are statistically significant at the $1 \%$ level, except the coefficients for $\delta$ (column 1), and $s_{\min }$ (column 3), which are not significant.

\section{F. Social Welfare}

We begin with the derivation of the consumer surplus. The utility of the representative consumer is given by

$$
U(\boldsymbol{q}, m)=a \sum_{i=1}^{n} q_{i}-\frac{1}{2} \sum_{i=1}^{n}\left(q_{i}\right)^{2}-\sum_{i=1}^{n-1} q_{i} \sum_{j=i+1}^{n}\left(1-s_{i j}\right) q_{j}+m
$$

where $s_{i j}$ is the degree of differentiation between the product of firm $i$ and the product of firm $j$. Let

$$
A=\sum_{i=1}^{n-1} q_{i} \sum_{j=i+1}^{n}\left(1-s_{i j}\right) q_{j}
$$


Since the first $k$ firms are RJV members and the next $n-k$ firms are non members, one can develop $A$ as follows:

$$
\begin{aligned}
A & =\sum_{i=1}^{k} q_{i}\left(\sum_{j=i+1}^{k}\left(1-s_{i j}\right) q_{j}+\sum_{j=k+1}^{n}\left(1-s_{i j}\right) q_{j}\right)+\sum_{i=k+1}^{n-1} q_{i} \sum_{j=i+1}^{n}\left(1-s_{i j}\right) q_{j} \\
& =\sum_{i=1}^{k} q_{i} \sum_{j=i+1}^{k}(1-s) q_{j}+\sum_{i=1}^{k} q_{i} \sum_{j=k+1}^{n}(1-\bar{s}) q_{j}+\sum_{i=k+1}^{n-1} q_{i} \sum_{j=i+1}^{n}(1-\bar{s}) q_{j} .
\end{aligned}
$$

The first term of $A$ can be rewritten as

$$
\sum_{i=1}^{k} q_{i} \sum_{j=i+1}^{k}(1-s) q_{j}=(1-s)\left(q_{R}\right)^{2} \frac{k(k-1)}{2}
$$

the second term as

$$
\sum_{i=1}^{k} q_{i} \sum_{j=k+1}^{n}(1-\bar{s}) q_{j}=(1-\bar{s}) q_{R} q_{-R}(n-k) k,
$$

and finally the third term as

$$
\sum_{i=k+1}^{n-1} q_{i} \sum_{j=i+1}^{n}(1-\bar{s}) q_{j}=(1-\bar{s})\left(q_{-R}\right)^{2} \frac{(n-k)(n-k-1)}{2}
$$

Summing up, $A$ can be rewritten as follows:

$$
A=(1-s)\left(q_{R}\right)^{2} \frac{k(k-1)}{2}+(1-\bar{s}) q_{R} q_{-R}(n-k) k+(1-\bar{s})\left(q_{-R}\right)^{2} \frac{(n-k)(n-k-1)}{2} .
$$

Now, we compute the total price paid by the representative consumer,

$$
\begin{aligned}
\sum_{i=1}^{n} p_{i} q_{i} & =\sum_{i=1}^{n} q_{i}\left(a-q_{i}-\sum_{i \neq j}\left(1-s_{i j}\right) q_{j}\right) \\
& =a \sum_{i=1}^{n} q_{i}-\sum_{i=1}^{n}\left(q_{i}\right)^{2}-\sum_{i=1}^{n} q_{i} \sum_{i \neq j}\left(1-s_{i j}\right) q_{j} .
\end{aligned}
$$

Notice that, by symmetry, we have

$$
\sum_{i=1}^{n} q_{i} \sum_{i \neq j}\left(1-s_{i j}\right) q_{j}=2 \sum_{i=1}^{n-1} q_{i} \sum_{j=i+1}\left(1-s_{i j}\right) q_{j}=2 A .
$$


Therefore, the consumer surplus can be written as

$$
C S=U(\boldsymbol{q}, m)-\sum_{i=1}^{n} p_{i} q_{i}=\frac{1}{2} \sum_{i=1}^{n}\left(q_{i}\right)^{2}+A+m
$$

Replacing the expression of $A$ in (A4), we find that

$C S=\frac{1}{2}\left[k(k+s-k s) q_{R}^{2}+[n-k+(1-\bar{s})(n-k)(n-k-1)] q_{-R}^{2}+2 k(n-k)(1-\bar{s}) q_{-R} q_{R}\right]+m$.

Net profit of member and non-member firms are

$$
\begin{gathered}
\Pi_{R}^{*}(k, \bar{\alpha})=\pi_{R}^{*}(k, s(\bar{\alpha}))-\left[d(1)-\frac{k-1}{k} d(\bar{\alpha})\right], \\
\Pi_{-R}^{*}(\bar{\alpha})=\pi_{-R}^{*}(s(\bar{\alpha}))-d(1),
\end{gathered}
$$

where $\pi_{R}^{*}$ and $\pi_{-R}^{*}$ are defined in Appendix A1. Therefore, the industry profits are

$$
P S=k \pi_{R}^{*}(k, s(\bar{\alpha}))-k\left[d(1)-\frac{k-1}{k} d(\bar{\alpha})\right]+(n-k)\left(\pi_{-R}^{*}(s(\bar{\alpha}))-d(1)\right) .
$$

